\title{
Relative Genotoxic Effects of Cypermethrin, Alphamethrin and Fenvalerate on the Root Meristems of Allium cepa
}

\author{
Bandaru V. Rao*, Tanikella L. Narasimham and Muktinutalapati V. Subbarao
}

Department of Botany, Andhra University, Waltair-530003, India

Received March 28, 2005; accepted May 17, 2005

\begin{abstract}
Summary The present investigation deals with the effects of 3 synthetic pyrethroid insecticides viz., Cypermethrin, Alphamethrin and Fenvalerate on the mitotic activity and mitotic chromosomes in the root meristems of Allium cepa. Root meristems were exposed to 4 different concentrations of each test compound for $1 \mathrm{~h}$ pulse treatment and allowed to different recovery periods.

Cytological analyses revealed that the test compounds elicited varying degrees of cytotoxic, turbagenic (toxicity to spindle) and clastogenic effects. In the ultimate analysis, Cypermethrin and Alphamethrin have more turbagenic and weak clastogenic activity whereas Fenvalerate has relatively strong clastogenic activity in vitro.
\end{abstract}

Key words Genotoxicity, Synthetic pyrethroid insecticides, Allium test.

Use of pesticides has become a necessary evil in the crop protection management programmes. Synthetic pyrethroids are new generation pesticides, which include more than 1000 powerful broad-spectrum insecticides. In general, synthetic pyrethroids are less toxic to mammals than the organophosphate, carbamate and organochlorine pesticides. This coupled with the efficacy of synthetic pyrethroids made them logical alternative to organochlorines and carbamates in pest control programmes (Elliot et al. 1978, Leahey 1985, Litchfield 1985). Nevertheless, the wide usage of pesticides in agricultural practices and public health programmes gave rise to concerns on the deleterious effects of these chemicals on non-target organisms (Grover and Malhi 1985). Screening of pesticides for their genotoxic effects in various assay systems unfolded alarming implications.

With very little information available on the genotoxicity and mutagenicity of pyrethroids, the present study is undertaken to assess the clastogenic and turbagenic effects of 3 synthetic pyrethroids using Allium test as the assay system (Fiskesjo 1985, Grant 1978, 1994, Sharma 1983).

\section{Materials and methods}

Root meristems raised from common onion (Allium cepa L. $2 n=16$ ) were used as assay system. Three insecticides tested in this study are [Cypermethrin (Devicyper 10\% EC), $\alpha-S$ cyanophenoxybenzyl-2,2-dimethyl-3S-(2',2'-dichlorovinyl)-1R-cyclopropanecarboxylate, Alphamethrin (Farsa $10 \%$ EC), $\alpha$-S cyanophenoxybenzyl-2,2-dimethyl-3R-(2',2'-dichlorovinyl)-1S-cyclopropanecarboxylate and Fenvalerate (Triumphcard $20 \%$ EC), $\alpha$-cyano-( $m$-phenoxybenzyl)-2-( $p$-chlorophenyl)-3-methylbutyrate] (Fig. 1). Prior to the initiation of the experiment 1 per cent stock solutions were prepared by dissolving the test compounds in 1-2 drops of acetone and subsequently dilution in distilled water (volume/volume). Subsequent dilutions were made in phosphate buffer adjusted to $\mathrm{pH}$ 7.0. The range of test concentrations of each chemical was selected basing on cytotoxic threshold of each chemical (by $\mathrm{LD}_{50}$ method) to the test system. Meristems of roots, $2-3 \mathrm{~cm}$ in length were exposed to the test solutions of different concentrations for $1 \mathrm{~h}$ followed by $0,4,12,24$

*Corresponding author, e-mail: bandaruvrao@yahoo.co.in 
and $48 \mathrm{~h}$ of recovery in Hoagland's nutrient solution. After the exposure and recovery regimen, 10 roots from diiferent onion bulbs were excised, washed thoroughly and fixed in aceticalcohol $(1: 3)$ for $1 \mathrm{~d}$ and stored in $70 \%$ alcohol for further analyses. For cytological observations, the fixed roots were hydrolyzed at $60^{\circ} \mathrm{C}$ for $6 \mathrm{~min}$ in $1 \mathrm{~N} \mathrm{HCl}$ and stained in Leuco Basic Fuchsin for 10-20 min (Darlington and La Cour 1976). The deeply stained region of the root tips were squashed in $1 \%$ carmine solution and wax ringed. All observations were made from these temporary slides. For each variable 5-6 root tip squashes were made and a minimum of 600 cells in metaphase/anaphase were counted in order to assess the clastogenic and turbagenic manifestations (Brogger 1979). Water controls were maintained simultaneously in order to study the spontaneous aberrations. The data relating to mitotic index were subjected to student's $t$-test to assess the differences on the impact of the 3 test pesticides on mitotic index.
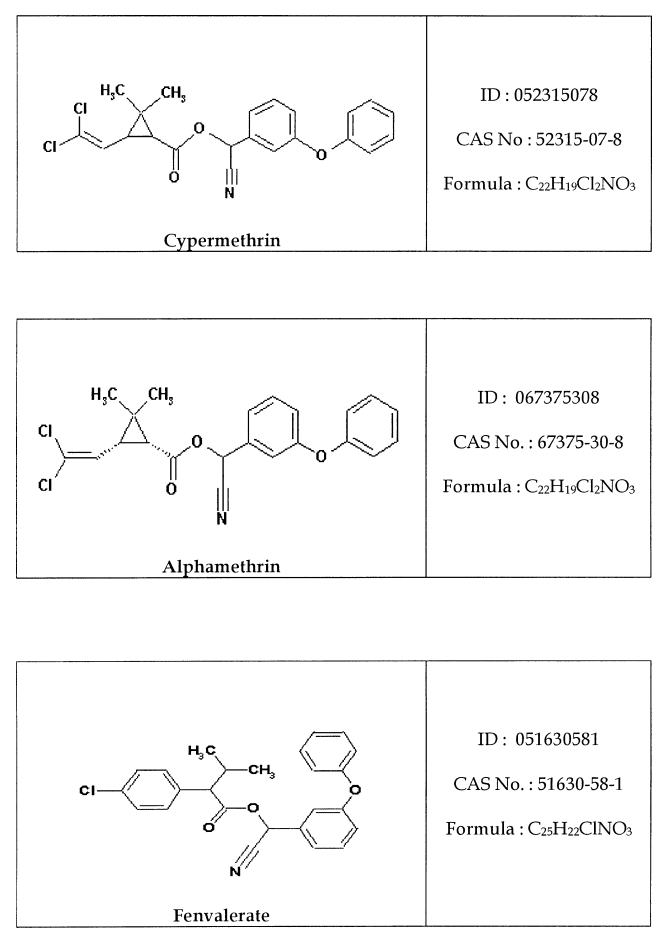

Fig. 1. Structures of the tested insecticides.

\section{Observations}

Data on the effects of different concentrations of the pyrethroid insecticides on mitotic index are shown in Tables $1-3$. At $0 \mathrm{~h}$ recovery, mitotic indices were reduced correspondingly to the increasing concentrations of Alphamethrin. Although Fenvalerate exposures reduced mitotic indices, the mitotic inhibition was not dose dependent. However, in both the cases, the treated roots attained normal mitotic activity in the subsequent recovery periods. Contrary to the mitodepressive (inhibition of mitotic activity) effect of Alphamethrin and Fenvalerate, roots treated with different concentrations of Cypermethrin exhibited enhanced mitotic activity when compared to controls.

In the present investigation, cytotoxicity, turbagenicity and clastogenicity are represented from the average frequencies of different manifestations for each concentration.

\section{Cytotoxicity}

All the insecticidal treatments induced cytotoxic manifestations like pycnosis and clumped metaphases. Persistence of pycnosis was observed even at 24 and $48 \mathrm{~h}$ recoveries of post-treatment. Cells with clumped metaphases are another cytotoxic phenomenon observed in the present study. Cells at metaphase containing entangled mass of chromosomes with no distinguishable contours were noticed with the 3 insecticidal treatments. Among the 3 test pesticides, Cypermethrin induced higher frequency of cells with clumped metaphases when compared to Alphamethrin and Fenvalerate. Chromatic erosion leading to uniformly lightly stained condition of the entire cell was noticed at higher concentrations of the Cypermethrin and Alphamethrin.

\section{Turbagenicity}

C-metaphases were a common phenomenon observed with all the insecticidal treatments. Concentration-related increase in the frequency of cells with $\mathrm{C}$-metaphase configurations was noticed 


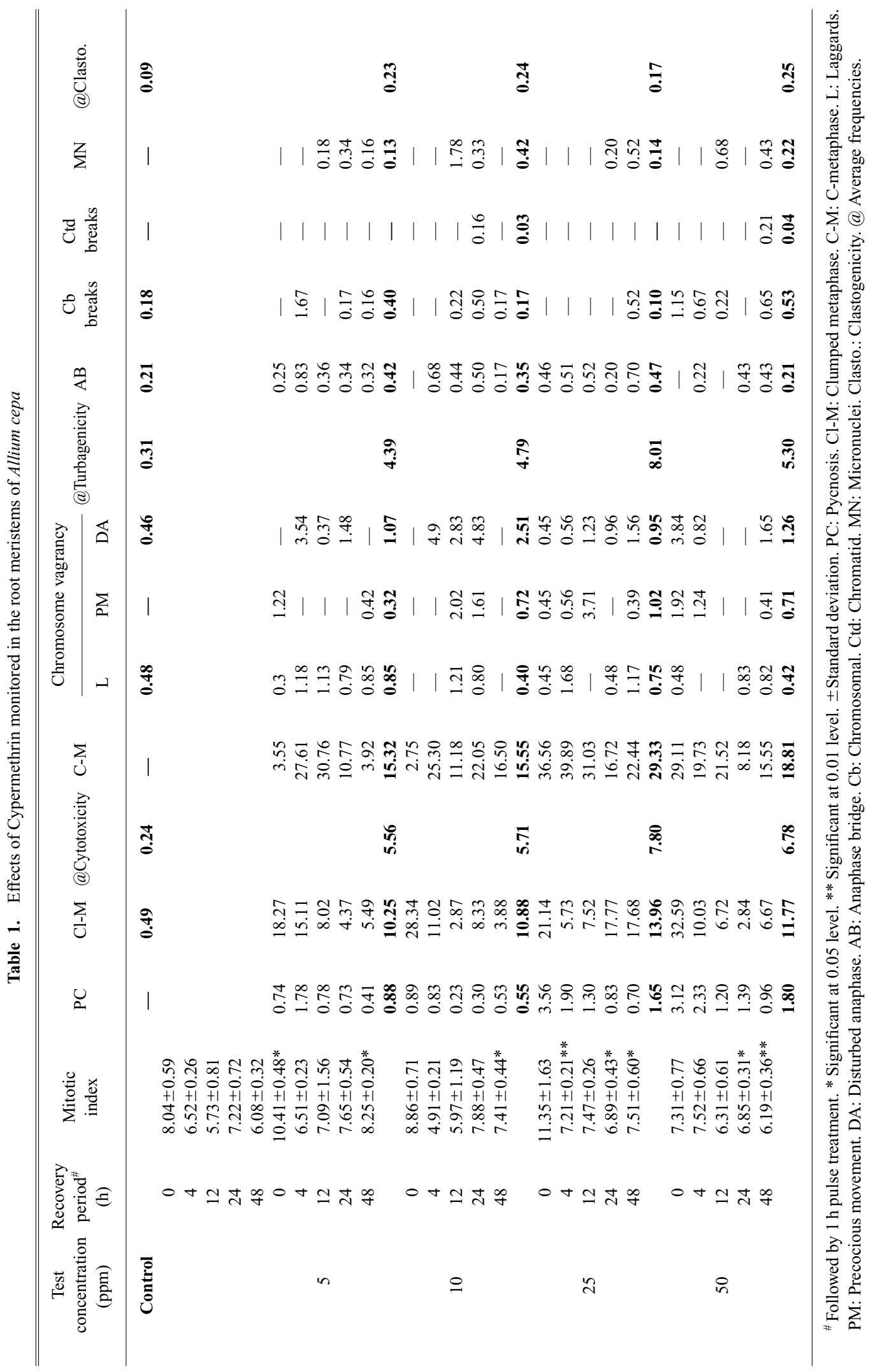




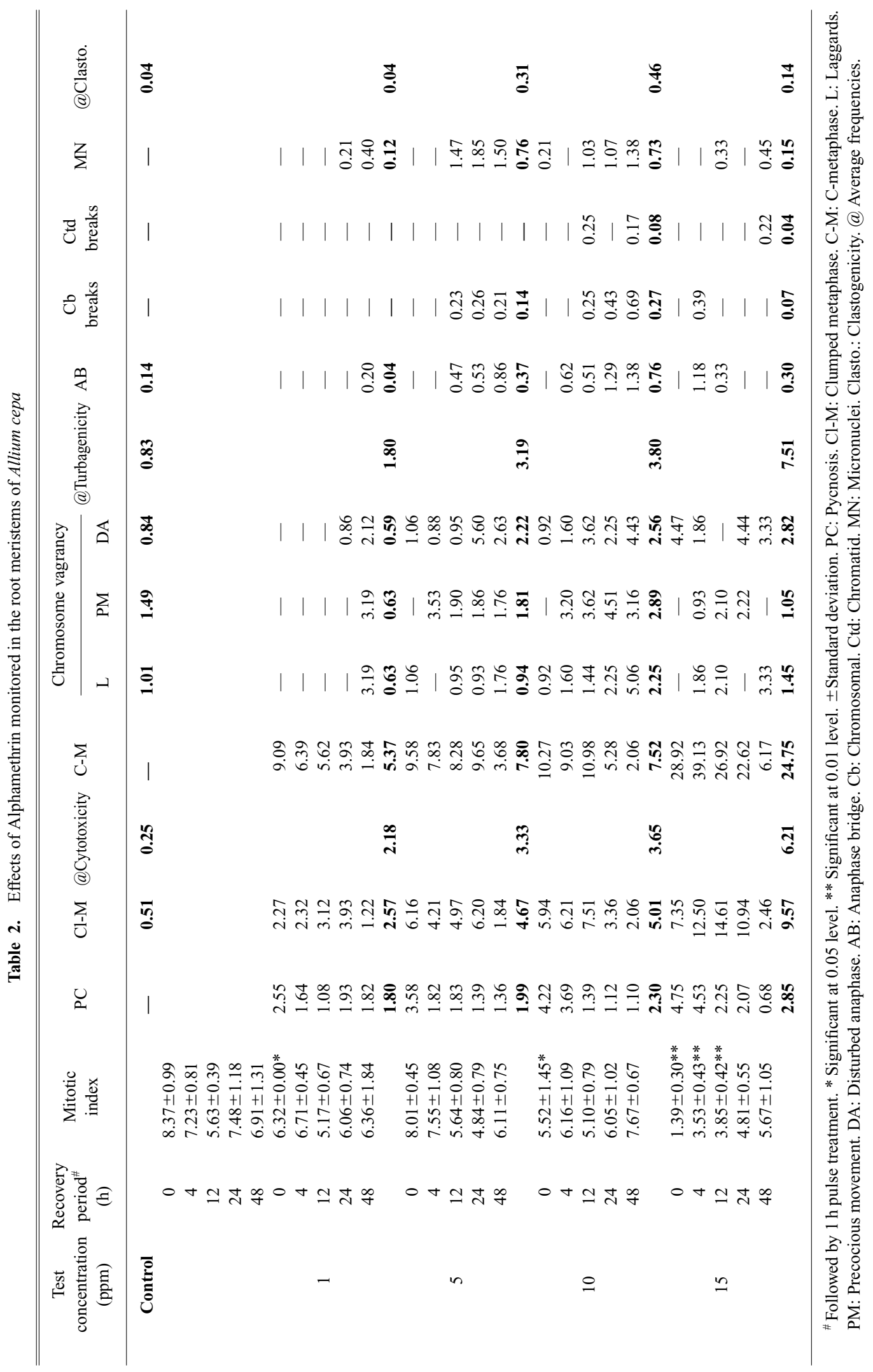




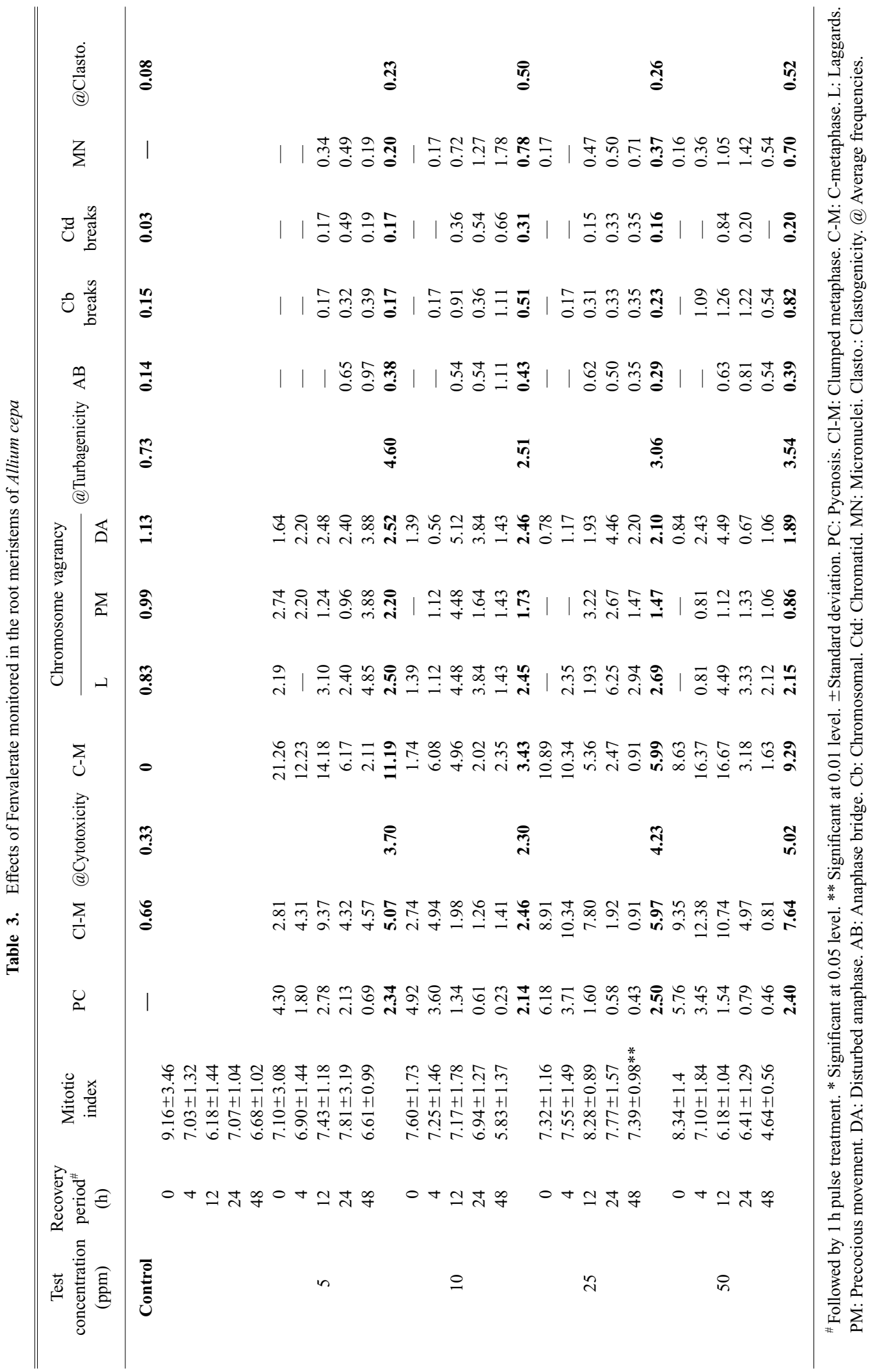


with both Alphamethrin and Fenvalerate treatments. Of the 3 insecticides tested, Cypermethrin was found to be the most effective in inducing higher frequency of cells with C-metaphase configurations.

The different concentrations of the 3 insecticides induced spindle disorders like laggards, precocious movement and disturbed anaphases to varying degrees. These 3 types of turbagenic manifestations are collectively treated under single category as chromosome vagrancy. Alphamethrin and Fenvalerate induced higher frequency of chromosome vagrancy when compared to Cypermethrin. However, considering the overall turbagenic effect, Cypermethrin and Alphamethrin were found to be more turbagenic when compared to Fenvalerate.

\section{Clastogenicity}

Anaphase bridge was the most frequently encountered clastogenic manifestation observed with all the pesticidal treatments. Roots exposed to Fenvalerate showed higher frequency of anaphase bridges when compared to Alphamethrin, whereas treatments with Cypermethrin produced very low frequency of anaphase bridges. Fenvalerate induced both chromosomal and chromatid breaks in equal proportion, whereas both Cypermethrin and Alphamethrin induced more or less equal number of cells with chromosome breaks but failed to induce cognizable number of cells with chromatid breaks. At all concentrations, Fenvalerate was found to be effective in inducing consistent frequency of cells with micronuclei. At 5 and $10 \mathrm{ppm}$ concentrations, Alphamethrin induced highest frequency of cells with micronuclei when compared with the other 2 insecticides.

\section{Discussion}

The observed increase in the frequency of mitotic indices values in root meristems treated with Cypermethrin may be the result of accumulation of C-metaphase configurations (Badr 1983). However, treatments with Alphamethrin and Fenvalerate induced mitodepression (inhibition of mitotic activity) at $0 \mathrm{~h}$ recovery. The induction of mitodepression by the pyrethroids is not a deviant phenomenon (Agarwal et al. 1994, Chauhan et al. 1986, Surrallaes et al. 1995). However, the initial mitodepressive effect of Alphamethrin and Fenvalerate is found to be transitory. The cytotoxicity exerted by the 3 tested compounds can be attributable to the methyl groups in the cyclopropane ring of pyrethriods (Surrallaes et al. 1995). The initial effects of cytotoxicity induced by the 3 pesticidal treatments, however, are ephemeral as evidenced by a concentration-related recovery in the posttreatment recoveries. All the pesticidal treatments impaired spindle mechanisms to varying degrees leading to chromosome vagrancies as well as C-metaphases. Inhibition of ATPases by the pyrethroids might be the cause of spindle disorganization (Reddy and Bashamohideen 1991). Several herbicides and insecticides have reported to produce similar type of effects (Badr 1983, de Kergommeaux et al. 1983, Panda et al. 1979). Most of the chromosomal breaks observed in the present study were at the centromeric region, indicative of a heterochrmatic action. Of the 3 pesticides tested, only Fenvalerate induced considerable frequency of cells with chromatid breaks. While the chromosomal breaks indicated the effect of these pesticides at pre-synthetic stage of cell cycle, Fenvalerate affects both at pre-synthetic as well as post-synthetic stages of DNA of a cell cycle (Kihlman 1975, Chauhan et al. 1999). In the present investigation all the 3 test insecticides produced chromatin bridges at anaphase, which were mostly single; but occasionally double bridges were encountered in the meristems of Allium cepa. These are formed by dicentric chromosomes, which appear as characteristic chromatin bridges at anaphase. Breaking-up of chromosomes followed by proximal chromatid reunion evidently led to the formation of such dicentric chromosomes (Tomkins and Grant 1972, Kaur and Grover 1985). Micronuclei observed with the 3 insecticides may be attributable due to either clastogenic events of the cells concerned or the result of single or a group of chromosomes forming individual nuclei. Basing on the size of the micronuclei observed in 
the present study, most of the micronuclei observed might be the product of the latter phenomenon (Degrassi and Rizzoni 1982, Sparrow and Singleton 1953).

\section{References}

Agarwal, D. K., Chauhan, L. K. S., Gupta, S. K. and Sundararaman, V. 1994. Cytogenetic effects of deltamethrin on rat bone marrow. Mutat. Res. 311: 133-138.

Badr, A. 1983. Cytogenetic activities of triazine herbicide in root tips of Allium cepa and Vicia faba. Mutat. Res. 117: $173-182$.

Brogger, A. 1979. Chromosome damage in human mitotic cells after in vivo and in vitro exposure to mutagens. In: Berg, O. (ed.). Genetic Damage in Man caused by Environmental Agents. Academic Press, New York. pp. 87-99.

Chauhan, L. K. S., Dikshith, T. S. and Sundararaman, V. 1986. Effects of deltamethrin on plant cells. 1. Cytological effects on the root meristems of Allium cepa. Mutat. Res. 171: 25-30.

-, Saxena, P. N. and Gupta, S. K. 1999. Cytogenetic effects of cypermethrin and fenvalerate on the root meristem cells of Allium cepa. Envtl. Exptl. Bot. 42: 181-189.

Darlington, C. D. and La Cour, L. E. 1976. The Handling of Chromosomes. 6th edition. Allen and Unwin, London. p. 201.

Degrassi, F. and Rizzoni, M. 1982. Micronucleus test in Vicia faba root tips to detect mutagen damage in fresh water Pollution. Mutat. Res. 97: 19-33.

de Kergommeaux, D. J., Grant, W. F. and Sandhu, S. S. 1983. Clastogenic and physiological responses of chromosomes to nine pesticides in the Vicia faba in vivo root tip assay system. Mutat. Res. 124: 69-84.

Elliot, M., James, N. F. and Potter, C. 1978. The future of pyrethroids in insect control. Ann. Rev. Entomol. 23: $443-469$.

Fiskesjo, G. 1985. The Allium test as a standard in environmental monitoring. Hereditas 102: 99-112.

Grant, W. F. 1978. Chromosomal aberrations in plants as a monitoring system. Environ. Health Perspect. 27 : $37-43$.

- 1994. The present status of higher plant bioassays for the detection of environmental mutagens. Mutat. Res. 310: $175-185$.

Grover, I. S. and Malhi, P. K. 1985. Genotoxic effects of some organophosphorous pesticides. 1. Induction of micronuclei in bone marrow cells in rat. Mutat. Res. 155: 131-134.

Kaur, P. and Grover, I. S. 1985. Cytological effects of some organophosphorous pesticides. 1. Mitotic effects. Cytologia 50: 187-197.

Kihlman, B. A. 1975. Root tips of Vicia faba for the study of chromosomal aberrations. Mutat. Res. 31: 401.

Leahey, J. P. 1985. The Pyrethroid Insecticides. Taylor and Francis, London.

Litchfield, M. H. 1985. Toxicity to mammals. In: Leahey, J. P. (ed.). The Pyrethroid Insecticides. Taylor \& Francis, London.

Panda, B. B., Sahu, R. K. and Sharma, C. B. S. R. 1979. Cytogenetic hazards from agricultural chemicals. Mutat. Res. 67: 161-166.

Reddy, P. M. P. G. H. and Bashamohideen, H. 1991. Inhibition of $\mathrm{Mg}^{+2}$ and $\mathrm{Na}^{(+)}-\mathrm{K}^{+}$ATPases in selected tissues of fish, Cyprinus carpio under fenvalerate toxicity. Biochem. Int. 23: 715-721.

Sharma, C. B. S. R. 1983. Plant meristems as monitors of genetic toxicity of environmental chemicals. Curr. Sci. 52: 1000-1002.

Sparrow, A. H. and Singleton, W. R. 1953. The use of radio-cobalt as a source of gamma-rays and some effects of chronic irradiation on growing plants. Amer. Nat. 87: 29-48.

Surrallaes, J., Xamena, N., Creus, A., Catalan, J., Naroppa, H. and Marcos, R. 1995. Induction of micronuclei by five pyrethroid insecticides in whole-blood and isolated human lymphocyte cultures. Mutat. Res. 341: 169-184.

Tomkins, D. J. and Grant, W. F. 1972. Comparative cytological effects of the pesticides: Menazon, Metrobromuron and Tetrachloro-isophthalonitile in Hordeum and Tradescantia. Can. J. Genet. Cytol. 14: 245-256. 